\title{
Effects of methylene blue on postoperative low-back pain and functional outcomes after lumbar open discectomy: a triple-blind, randomized placebo-controlled trial
}

\author{
Majid Reza Farrokhi, MD, ${ }^{1}$ Mehrzad Lotfi, MD, ${ }^{2}$ Mohammad Sadegh Masoudi, MD, ${ }^{1}$ and \\ Mehrnaz Gholami, MA ${ }^{1}$
}

${ }^{1}$ Shiraz Neuroscience Research Center and Neurosurgery Department, and ${ }^{2}$ Radiology Department, Shiraz University of Medical Sciences, Shiraz, Iran

\begin{abstract}
OBJECTIVE Despite advances in surgical and anesthesiology techniques, many patients continue to experience postoperative pain after lumbar disc operations. This study aims to investigate the effects of methylene blue (MB) on preventing postoperative low-back pain (LBP) with or without radicular pain and improving the quality of life (QOL) in patients undergoing lumbar open discectomy.
\end{abstract}

METHODS This is a prospective, randomized, triple-blind, placebo-controlled clinical trial, which was conducted at Shiraz University of Medical Sciences between July 2011 to January 2012. Of a total of 130 patients, 115 were eligible for participation; 56 received $1 \mathrm{ml}$ of MB solution at a concentration of $0.5 \%$ (MB group) and 59 received an equivalent volume of normal saline (control group). Primary outcomes were the control of LBP with or without radicular pain, which was evaluated preoperatively and at 24 hours and 3 months after surgery with the use of a visual analog scale (VAS), and the improvement of QOL, which was assessed preoperatively and 3 months postoperatively by means of the Persian translation of the Oswestry Disability Index questionnaire.

RESULTS The mean VAS scores for LBP were significantly lower in the MB group compared with the control group at 24 hours ( $1.25 \pm 0.97$ vs $2.80 \pm 0.69, p<0.001)$ and 3 months $(1.02 \pm 1.29$ vs $2.07 \pm 1.10, p=0.019)$ after treatment. The mean radicular pain scores decreased significantly in the 2 groups at 24 hours after surgery, but the mean radicular pain score was significantly lower in the MB-treated patients than the control group. However, the difference between radicular pain scores in the MB group (1 \pm 1.1$)$ and the control group $(1.2 \pm 1)$ was not statistically significant $(p=0.64)$. The reduction in LBP was greater in the MB group than the control group (8.11 \pm 1.74 vs $6.07 \pm 1.52, p=0.023, C l 95 \%$ -1.37 to -0.10$)$. The functional QOL improved significantly 3 months after the operation in both groups $(p<0.001)$. Moderate disability occurred more frequently in the control group than in the MB group ( $14.5 \%$ vs $7.7 \%, p=0.004)$. No toxicity, adverse effects, or complications were found in the group of patients treated with MB injection.

CONCLUSIONS A single dose of $\mathrm{MB}(1 \mathrm{ml} 0.5 \%)$ for coating the dura and surrounding tissues (facet and muscle) shows promising results in terms of safety, reduction of postoperative pain, and functional outcome compared with placebo.

Clinical trial registration no.: IRCT138807142193N4 (www.irct.ir)

http://thejns.org/doi/abs/10.3171/2015.3.SPINE141172

KEY WORDS postoperative pain; methylene blue; lumbar discectomy; low-back pain; quality of life

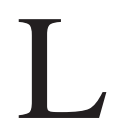

UMBAR discectomy is a common surgical procedure with a success rate of $60 \%$ to $90 \%, 8,57$ and lowback pain (LBP) is a leading cause of high health care costs. ${ }^{7}$ Despite progress in surgical techniques, some patients still suffer from postoperative pain. ${ }^{3,8}$ This leads to prolonged hospital stays and increased cost. Generally, many drugs such as steroidal and nonsteroidal anti- inflammatory drugs, analgesics, sedatives, and narcotics are commonly prescribed for pain management after surgery. 1,10,19,24,29,39 Although several methods have been introduced for postoperative pain control in spinal surgeries, this problem remains noteworthy. The mechanism of pain can be mechanical or chemical. ${ }^{14}$ Postoperative mechanical back pain associated with same-level degeneration is

ABBREVIATIONS BMI = body mass index; LBP = low-back pain; MAO = monoamine oxidase; $M B$ = methylene blue; ODI = Oswestry Disability Index; $Q \mathrm{QL}=$ quality of life; SSRI = selective serotonin reuptake inhibitor; ST = serotonin toxicity; VAS = visual analog scale; 5-HT = 5-hydroxytryptamine (serotonin).

SUBMITTED November 19, 2014. ACCEPTED March 26, 2015.

INCLUDE WHEN CITING Published online September 11, 2015; DOI: 10.3171/2015.3.SPINE141172. 
common in patients undergoing single-level lumbar discectomy. ${ }^{30}$ Pain management surveys indicate that many patients suffer unrelieved pain, in part, because most analgesia is provided on demand after the patient is in pain. ${ }^{10}$ Although there are many analgesic drugs available for postoperative pain, many patients still find them to be suboptimal for controlling pain. ${ }^{29}$ Intraoperative injection of local anesthetic (bupivicaine or lidocaine) to the superficial tissues and intravenous, oral, or rectal administration of opioid or other analgesics after operation are standard methods of postoperative pain reduction, but inadequate analgesia, constipation, and delayed mobilization are frequent adverse effects of these treatments. ${ }^{1}$ Some studies have shown that using agents such as Adcon-L, Oxiplex/ SP gel, or gabapentin did not result in a significant reduction in pain intensity following lumbar discectomy. ${ }^{19}$ Systematic reviews of randomized controlled trials have demonstrated the benefits of nonsteroidal antiinflammatory drugs in reducing postoperative pain in patients undergoing posterior lumbar discectomy, laminectomy, or spinal fusion. ${ }^{24,39}$ Nevertheless, outcome after lumbar discectomy for LBP and radicular pain is variable, and the benefit is inconsistent. ${ }^{8}$ Given the prevalence of this problem and the limited treatment options, the development of any alternative treatment method should be welcome.

Methylene blue (MB) is a low-molecular weight, partially liposoluble vital dye, which has been used in many different areas of clinical medicine since $1876 .{ }^{53}$ Different theories underlie the pharmacological and therapeutic mechanisms that may be responsible for the effect of $\mathrm{MB}$, including the inhibition of free-radical generation, ${ }^{16}$ deactivation of xanthine oxidase, ${ }^{41}$ inhibition of the production of nitric oxide (which has been implicated in the inflammatory processes of disc degeneration and discogenic pain), $4,17,25$ destruction of free nociceptive nerve endings for the relief of pain, ${ }^{27,50}$ reduction of neurotoxic structural and functional damage in brain parenchyma, ${ }^{38}$ its effectiveness as a neuroprotective compound, ${ }^{51}$ its anxiolytic and antidepressant activities,,$^{18,28,42}$ and inhibition of monoamine oxidase (MAO). ${ }^{52}$ The mechanism by which MB exerts its anxiolytic and antidepressant effects has been linked to actions on MAO-A as well as nitric oxide synthase..$^{18}$ In fact, MB is a potent reversible inhibitor of $\mathrm{MAO}-\mathrm{A}$ and thus will influence 5-hydroxytryptamine (5HT, serotonin) levels at doses expected during MB infusion. Serotonin (5-HT) is present in central and peripheral serotonergic neurons, it is released from platelets and mast cells after tissue injury, and it exerts analgesic effects depending on the site of action and the receptor subtype.

Based on several studies showing the safety and efficacy of the low dose of MB solution in systemic and epidural administration, ${ }^{13,22,32,49}$ we designed this randomized, placebo-controlled, triple-blind study to evaluate the effect of MB on postoperative LBP and radicular pain and quality of life (QOL) in patients with lumbar discectomy.

\section{Methods \\ Study Population}

This prospective, randomized, triple-blind, placebocontrolled clinical trial was performed in 130 patients in Nemazee and Chamran hospitals, both tertiary health care centers affiliated with Shiraz University of Medical Sciences, from July 2011 to January 2012. The study was designed in compliance with the CONSORT guidelines for clinical trials. ${ }^{43}$ The medical research ethics committee as well as institutional review board of Shiraz University of Medical Sciences approved the study proto$\mathrm{col}$ and the trial was registered (registration number ID: IRCT138807142193N4) in the Iranian Registry of Clinical Trials (www.irct.ir), which is a primary registry in the WHO Registry Network set up with the help of the Ministry of Health and Medical Education and hosted by Iran University of Medical Sciences. Written informed consent was obtained from all the patients before inclusion in the study, and the Helsinki Declaration guidelines for research were followed. We included those patients who underwent open lumbar discectomy in our centers during the study period. We excluded those patients who had a history of previous disc surgery, local or systemic infection, intraspinal tumor, spinal steroid injection or local anesthesia, or spinal instability; those patients receiving myelograms or lumbar punctures within 24 hours before surgery; those taking serotonergic psychiatric medications; and patients who needed spinal fusion. Of a total of 130 patients, 15 were excluded in accordance with the exclusion criteria, and 115 were eligible for participation. Unintended durotomy is a common complication in spine surgery that may lead to serious complications if not recognized. ${ }^{40}$ During the study follow-up period, the patients with unintended durotomies, i.e., an unintentional opening of dura during the operation, were excluded from the study.

\section{Randomization and Intervention}

The eligible patients were given an admission number from 1 to 115 based on their order of referral. They were randomly assigned to the intervention and control groups using a method of sequence generation (computerized random number generators). For this purpose, we prepared 115 sheets of paper, writing on 56 sheets "I" for "Intervention: $1 \mathrm{ml}$ of MB solution at a concentration of $0.5 \%$ " and on 59 "C" for "Control: $1 \mathrm{ml}$ of normal saline," and put each paper sheet in an envelope. The envelopes were then sorted randomly using random allocation software. With regard to the patients' admission number and the random allocation sequences, the physician who was the trial group coordinator opened the sealed envelopes and assigned each patient to the Intervention or Control group, accordingly. The group assignment remained concealed during the study.

The surgeon was therefore not aware of the drug administered and had no role in group assignment. The independent statistical analyst, who was not involved in any stage of these procedures, was also unaware of the trial groups until the data were analyzed and the labels were decoded. The patients were unconscious during the surgery, and thus they knew nothing about the type of intervention they received. All the patients were followed by 2 independent assessors who were unaware of the study (in addition to being blind to group assignment, they did not know that a study was being conducted). A third assessor, who was likewise unaware of the study, verified the results. These 
assessors, who were not members of the anesthesia or surgical team, recorded the patients' outcome data. The surgeon, assistant surgeon, statistician, patients, and assessors were all blinded to group assignment throughout outcome measurement and analysis. Accordingly, the trial was run as a triple-blind design.

\section{Drug Preparation}

Methylene blue was diluted by an independent blinded investigator who did not participate in the enrollment and postoperative evaluation. The MB solution was prepared by diluting $10 \mathrm{~g}$ of MB powder (M9140, Sigma-Aldrich) in $1 \mathrm{~L}$ of distilled water, and the solution was sterilized in an autoclave at a pressure of $20 \mathrm{lb}\left(1.5 \mathrm{~kg} / \mathrm{cm}^{2}\right)$ at $125^{\circ} \mathrm{C}$ for 1 hour. In the operation room, the physician poured the MB and normal saline into separate blue glass bottles and labeled each bottle as "I" and "C," respectively.

\section{Study Protocol}

All the patients underwent preoperative eligibility evaluations, including MRI of the spine and examination by a neurosurgeon. Patients' demographic information including age, sex, underlying diseases, duration of clinical symptoms, and the levels at which discectomy was to be performed were recorded before the surgery.

\section{Surgical Procedure}

General anesthesia was induced in all patients with thiopental $(5-7 \mathrm{mg} / \mathrm{kg})$ and fentanyl $(1-1.5 \mu \mathrm{g} / \mathrm{kg})$. Atracurium $(0.6 \mathrm{mg} / \mathrm{kg})$ was administered to facilitate endotracheal intubation. Anesthesia was maintained with a propofol infusion $100-200 \mathrm{mg} / \mathrm{kg} / \mathrm{min}$ and $70 \%$ nitrous oxide in oxygen and intermittent vecuronium when indicated. Radiographic localization was used to plan the skin incision, and the site was infiltrated with $10 \mathrm{ml}$ of $1 \%$ lidocaine. Laminectomy was performed, and then lumbar discectomy was performed at a single level (L4-5 or L5-S1) or at 2 levels (L4-5 and L5-S1). The herniated fragment and nucleus pulposus within the disc space were removed using curettes and rongeurs. A search for midline and foraminal fragments was routinely made, and a foraminotomy was performed if there was bony encroachment on the nerve. All the operations were performed by the same surgeon. The surgeon left the operating room after completion of the operation immediately before closure of the wound. An assistant surgeon, who was unaware of the study, administered either $1 \mathrm{ml}$ of MB solution at a concentration of $0.5 \%$ or an equivalent volume of normal saline over the dural sac and the surrounding soft tissues by a dark syringe that was previously prepared by the physician and was labeled with "I" or "C" and the patient's admission number. Meanwhile, the assistant surgeon was careful not to place any drop on the skin. He performed the wound closure using absorbable fascial sutures and a subcuticular skin suture and had no subsequent interaction with the patients. The patients were transferred to the postanesthesia care unit and they were assessed for any complications thereafter. A blinded assessor recorded the pain scores preoperatively, after the first 24 hours, and 3 months after the surgery. The early postoperative measurements were made 24 hours after the completion of surgery. During the first 24 hours after surgery, the patients in each group received a single 4-mg intravenous dose of morphine without using any continuous infusion on an as-needed basis when they had severe pain and their visual analog scale (VAS ${ }^{20}$ score was greater than 6 . No other sedatives or analgesics were given to the patients during the follow-up period. The patients were evaluated again at the 3-month follow-up visit. We did not organize a medication program for postoperative pain management in our patients in outpatient settings so we didn't prescribe any medication treatment at all for pain management in our patients to avoid any intervention in our study.

\section{Outcome Measures}

Primary outcomes were the control of LBP with or without radicular pain, which was evaluated preoperatively and at 24 hours and 3 months after surgery, and the improvement of QOL or functional daily activity, which was assessed preoperatively and 3 months postoperatively. Severity of early postoperative LBP and radicular pain was evaluated using the Huskisson VAS, ${ }^{20}$ with scores ranging from 1 (no pain) to 10 (excruciating pain). The day before surgery, patients were informed how to use the VAS. QOL was evaluated by a questionnaire based on the Oswestry Disability Index (ODI) version 2, which is a functional disability measurement of QOL comprising 6 items in 10 dimensions: pain intensity, personal care, lifting, walking, sitting, standing, sleeping, social life, traveling, and change in the degree of pain. ${ }^{12}$ Because the ODI was developed for English speaking patients, we used its Persian translation (with permission from the School of Rehabilitation, affiliated with Tehran University of Medical Sciences). The patients completed the Persian translation of the ODI questionnaire for measurement of the severity of disability in the lumbar area. The Persian translation of this instrument may have retained some cultural or linguistic biases, but this problem is common to many studies that are conducted in non-native English-speaking settings.

\section{Statistical Analysis}

SPSS version 16.0 (SPSS Inc.) was used for data analysis. Power analysis of variance (ANOVA) was done with Power Analysis and Sample Size (PASS) software (NCSS). The analysis showed that a sample size of 52 patients (26 in each group) would be adequate; however, we studied 115 patients (56 participants in the study group and 59 in the control group) in order to allow for the possibility of attrition. Alpha was set at 0.05 , and the power calculation revealed a power of $90 \%$ for the study to detect a significant difference in VAS and ODI scores after 3 months. According to the sample size calculation in our study and regarding the preoperative scores for ODI and VAS, if we achieved a $20 \%$ difference in mean pain scores and $20 \%$ difference in ODI after 3 months, then we could detect a significant difference between the 2 groups in terms of VAS and ODI scores. Paired t-tests were used to compare results within groups; independent t-tests were used to compare results between the groups; chi-square tests were used to compare proportions. The paired t-test and 
Wilcoxon signed-rank test were used to compare differences in the VAS and ODI scores, respectively, before and after surgery. Quantitative data were expressed as mean \pm $\mathrm{SD}$, and qualitative data were reported as proportions. A 2 -sided $\mathrm{p}$ value less than 0.05 was considered statistically significant.

\section{Results}

During the study period starting in July 2011, 130 patients were selected for enrollment, and 115 of these were randomized (Fig. 1). Table 1 shows preoperative LBP, radicular pain and functional QOL scores in these patients. Of 115 patients, 8 were excluded after randomization (due to intraoperative durotomy, withdrawal of consent, or loss to follow-up) in the 2 groups during the follow-up period, and the 107 remaining patients, including 63 men $(58.9 \%)$ and 44 women (41.1\%) with a mean age of 41.5 \pm 11.2 years (range 18-77 years), finished the study and were included in the final analysis. Table 2 summarizes the baseline characteristics of these patients (52 in the MB group and 55 in the control group). There was no significant difference between the 2 groups regarding age, sex, body mass index (BMI), smoking, taking medications, number of discectomy levels, and the mean duration of symptoms. At the 3-month follow-up visit, the assessors asked the patients whether they used any medication during the follow-up period, and the results showed that only a few patients had used drugs for reducing pain while the
TABLE 1. Preoperative severity of LBP and radicular pain and functional QOL of the 115 patients in the 2 groups

\begin{tabular}{|c|c|c|c|}
\hline \multirow[b]{2}{*}{ Parameters } & \multicolumn{2}{|c|}{ Group } & \multirow[b]{2}{*}{$\begin{array}{c}\mathrm{p} \\
\text { Value }\end{array}$} \\
\hline & $M B(n=56)$ & $\begin{array}{l}\text { Placebo } \\
(n=59)\end{array}$ & \\
\hline $\begin{array}{l}\text { Severity of LBP, mean VAS } \\
\text { score }\end{array}$ & $9.13 \pm 0.886$ & $8.93 \pm 0.821$ & 0.631 \\
\hline $\begin{array}{l}\text { Severity of radicular pain, } \\
\text { mean VAS score }\end{array}$ & $8.4 \pm 1.6$ & $7.2 \pm 1.7$ & 0.39 \\
\hline Functional QOL, ODI score & $44.56 \pm 8.75$ & $44.84 \pm 5.27$ & 0.932 \\
\hline
\end{tabular}

remaining patients could manage their pain without using medications. During the first 24 hours after surgery, 3 patients (5.76\%) in the MB-treated group and 12 patients (21.8\%) in the control group had severe LBP and received a single 4-mg intravenous dose of morphine without any continuous infusion.

The data related to postoperative LBP and radicular pain are shown in Table 3. The mean preoperative radicular pain scores decreased significantly in the 2 groups at 24 hours after surgery $(8.4 \pm 1.6$ vs $1 \pm 1.1$ in the MB group and $7.2 \pm 1.7$ vs $1.2 \pm 1$ in the control group), but the mean radicular pain score was lower in the MB-treated patients than the control group at 24 hours after surgery (1 \pm 1.1 vs $1.2 \pm 1, \mathrm{p}=0.64$ ). The mean VAS scores for LBP were significantly lower in the MB group compared with

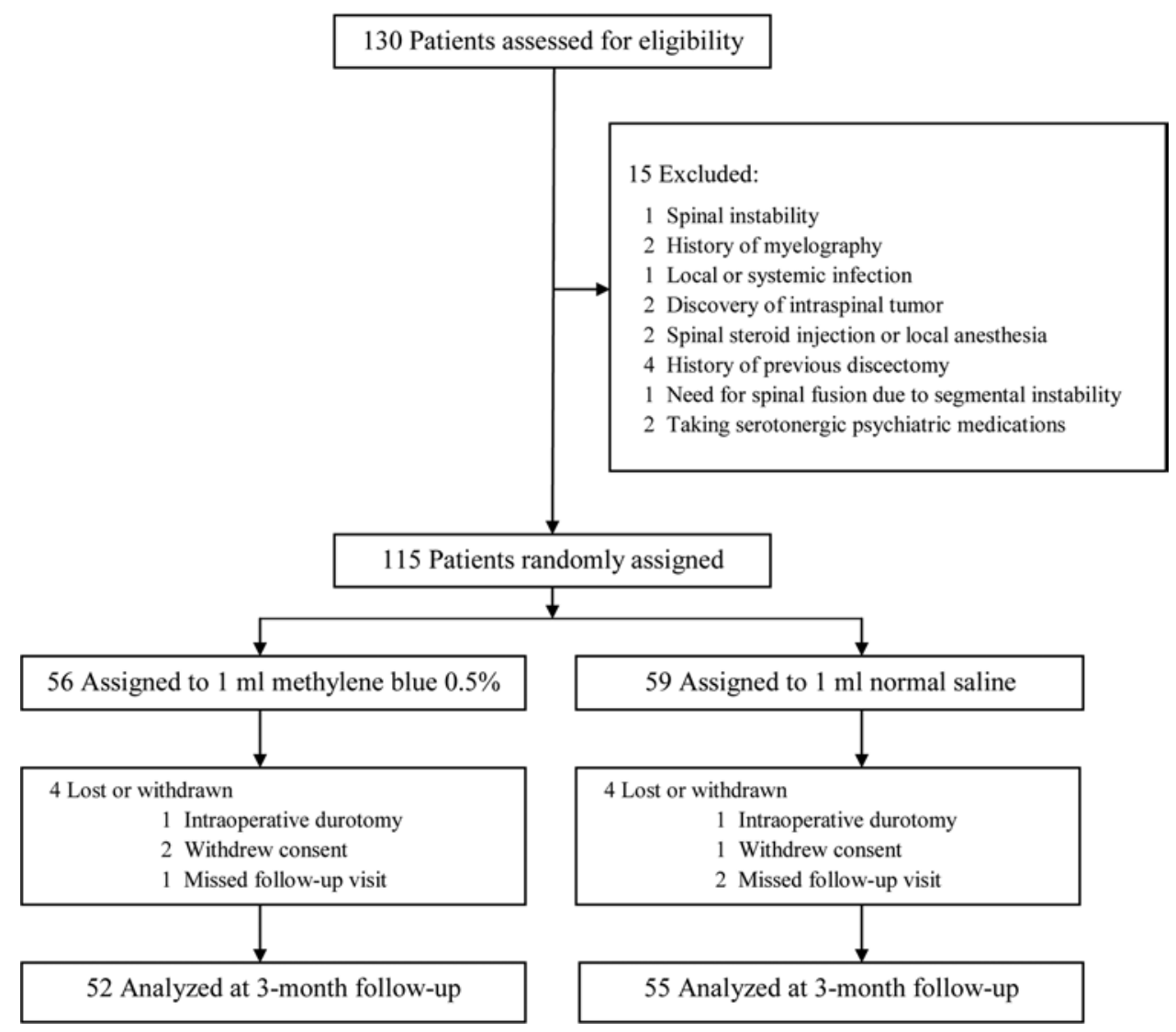

FIG. 1. CONSORT flow diagram showing enrollment, assigned intervention, and follow-up of the patients. 
TABLE 2. Baseline characteristics of 107 patients who underwent discectomy in the 2 study groups*

\begin{tabular}{|c|c|c|c|}
\hline \multirow[b]{2}{*}{ Characteristic } & \multicolumn{2}{|c|}{ Group } & \multirow[b]{2}{*}{$\mathrm{p}$ Value } \\
\hline & $M B(n=52)$ & $\begin{array}{l}\text { Placebo } \\
(n=55)\end{array}$ & \\
\hline Sex & & & 0.239 \\
\hline Male & $34(65.4 \%)$ & $29(52.7 \%)$ & \\
\hline Female & $18(34.6 \%)$ & $26(47.3 \%)$ & \\
\hline Age in yrs & & & 0.942 \\
\hline Mean & $41.6 \pm 11.5$ & $41.4 \pm 10.9$ & \\
\hline Range & $19-72$ & $18-77$ & \\
\hline $\mathrm{BMI}$ & $25.13 \pm 3.3$ & $24.9 \pm 3.7$ & 0.757 \\
\hline Normal, BMI $\leq 24.9$ kg/m² & $27(51.9 \%)$ & $29(52.7 \%)$ & 0.993 \\
\hline Overweight, BMI $\geq 25 \mathrm{~kg} / \mathrm{m}^{2}$ & $25(48 \%)$ & $26(47.3 \%)$ & \\
\hline Smoking & $10(19.2 \%)$ & $14(25.5 \%)$ & 0.493 \\
\hline Taking medication & $6(11.5 \%)$ & $10(18.2 \%)$ & 0.420 \\
\hline Mean duration of Sx in mos & $5.48 \pm 4.2$ & $5.53 \pm 5.1$ & 0.959 \\
\hline \multicolumn{4}{|l|}{ Number of discectomy levels } \\
\hline \multicolumn{4}{|l|}{ Single level (\%) } \\
\hline L4-5 & $27(51.9 \%)$ & $24(43.64 \%)$ & \\
\hline L5-S1 & $22(42.3 \%)$ & $29(52.73 \%)$ & \\
\hline \multicolumn{4}{|l|}{2 levels (\%) } \\
\hline L4-5 \& L5-S1 & $3(5.8 \%)$ & $2(3.63 \%)$ & \\
\hline
\end{tabular}

Sx = symptoms.

* Values represent numbers of patients (\%) unless otherwise indicated.

the control group at 24 hours $(1.25 \pm 0.97$ vs $2.80 \pm 0.69$, $\mathrm{p}<0.001)$ and 3 months $(1.02 \pm 1.29$ vs $2.07 \pm 1.10$, p = $0.019)$ after the operation; the severity of LBP showed a significant decrease in both groups at the 3-month followup evaluation. The reduction in the LBP in the MB group was significantly greater than in the control group $(8.11 \pm$ 1.74 vs $6.07 \pm 1.52, \mathrm{p}=0.023$, CI $95 \%-1.37$ to -0.10 ).

Table 3 shows that at 3 months' follow-up, the functional QOL improved significantly in both groups and there was a statistically significant difference between the 2 groups ( $<$ 0.001). The mean ODI score for the MB group at this time point was significantly lower than that for the control group $(9.58 \pm 8.56$ vs $15.53 \pm 7.21, \mathrm{p}<0.001)$ and there was a significant improvement in the functional QOL in the MB group at 3 months after the surgery. The ODI decreased significantly after the operation in both groups in comparison with preoperative ODI scores, but this reduction in the control group patients was more than the reduction in the MB group patients. Regarding functional disability, none of the patients showed severe disability (functional disability $>40 \%$ ) postoperatively. Therefore, only a comparison of minimal versus moderate disability was made for the statistical analysis between the 2 groups. There was no significant difference in the incidence of minimal disability between the 2 groups $(\mathrm{p}=0.12)$, but moderate disability occurred significantly more frequently in the control group than in the MB group (14.5\% vs $7.7 \% ; \mathrm{p}=0.004)($ Table 3$)$.

Intraoperative durotomy occurred in 2 patients (1 patient in the MB group and 1 patient in the control group),
TABLE 3. Outcomes after discectomy in the 2 study groups

\begin{tabular}{|c|c|c|c|}
\hline \multirow[b]{2}{*}{ Parameter } & \multicolumn{2}{|c|}{ Group } & \multirow[b]{2}{*}{$p$ Value } \\
\hline & $M B(n=52)$ & $\begin{array}{r}\text { Placebo } \\
(n=55)\end{array}$ & \\
\hline \multicolumn{4}{|l|}{ LBP, VAS score } \\
\hline 24 hrs postop & $1.25 \pm 0.97$ & $2.80 \pm 0.69$ & $<0.001^{*}$ \\
\hline 3 mos postop & $1.02 \pm 1.29$ & $2.07 \pm 1.10$ & $0.019^{*}$ \\
\hline Reduction in LBP & $8.11 \pm 1.74$ & $6.07 \pm 1.52$ & $0.023^{*}$ \\
\hline \multicolumn{4}{|l|}{ Radicular pain, VAS score } \\
\hline 24 hrs postop & $1 \pm 1.1$ & $1.2 \pm 1$ & 0.64 \\
\hline \multicolumn{4}{|l|}{ ODI } \\
\hline 3 mos after surgery & $9.58 \pm 8.56$ & $15.53 \pm 7.21$ & $<0.001^{*}$ \\
\hline Reduction in ODI & $34.9 \pm 12.8$ & $29.3 \pm 8.1$ & $0.008^{*}$ \\
\hline \multicolumn{4}{|l|}{ Functional disability $\dagger$} \\
\hline 0-20\%: minimal disability & $48(92.3 \%)$ & $47(85.5 \%)$ & 0.12 \\
\hline 20-40\%: moderate disability & $4(7.7 \%)$ & $8(14.5 \%)$ & $0.004^{*}$ \\
\hline
\end{tabular}

* Indicates a significant difference between the 2 groups.

$\dagger$ There were no patients in either group with severe disability (functional disability $>40 \%$ ).

who were subsequently excluded from the study (Fig. 1). None of the patients who received MB developed symptoms of nerve root injury, back pain aggravation or toxicity, including serotonin toxicity (ST) or other CNS toxicity, after the treatment. No side effects or complications related to the injection of $\mathrm{MB}$, including nausea, vomiting, or stomach pain, pain in the chest or behind the sternum, high fever, dizziness, or confusion, were recorded, and there was no wound infection or skin inflammation in any of the patients treated with MB.

\section{Discussion}

Postoperative pain relief provides benefits such as earlier mobilization, shorter hospital stay, reduced hospital costs, and morbidity reduction. In this study, our findings suggest that intraoperative administration of $\mathrm{MB}$ in patients undergoing discectomy is associated with a significant improvement in pain relief and functional QOL after the procedure. In our study, power of $>99 \%$ for LBP and $75 \%$ for ODI was reasonable to detect statistically significant results.

Analysis of our data showed a statistically significant difference in the VAS scores between the 2 groups. The MB-treated patients had significantly less LBP than the control group at 24 hours and 3 months after surgery. The findings of our study are consistent with the findings of 2 studies published by Peng and colleagues in $2007^{33}$ and in 2010,32 which evaluated the effect of intradiscal injection of MB for the treatment of patients with chronic discogenic LBP. In the first of the two publications, the authors reported that intradiscal MB injection resulted in a disappearance or marked alleviation of $\mathrm{LBP},{ }^{33}$ and in the second publication, they reported reductions of mean scores from 72 to 20 for pain. ${ }^{32}$ The results of these studies suggested that the injection of MB into the painful disc may be a very effective alternative for the surgical treatment of 
chronic discogenic LBP. ${ }^{32,33}$ Our findings are also similar to those of Kim et al. ${ }^{21}$ who reported that the average VAS score was reduced significantly from 5.1 at baseline to 3.2 at 3 months after intradiscal MB injection in patients with chronic discogenic LBP. They concluded that the intradiscal MB injection is a minimally invasive treatment that is effective in the short term and is indicated for discogenic back pain but may lose its effectiveness long term. In a study with findings that are in contrast to ours, Levi et al. ${ }^{23}$ used a single intradiscal injection of MB in patients with discogenic LBP and found no improvement in pain. The difference between their findings and ours might be explained by the small sample size (16 patients) used in their study.

Although lumbar discectomy may relieve radicular pain and LBP, more improvement can be expected in leg pain than in back pain. ${ }^{31}$ Some studies have found that a majority of patients experience no improvement of LBP. ${ }^{5,6,57}$ Usually, patients who have undergone laminectomy experience relief of radicular pain during the immediate postoperative period (within 24 hours) due to nerve root decompression, but the pain resulting from the manipulation of soft tissue, muscles, and facet joints decreases gradually during the first few weeks or months after surgery. ${ }^{35}$ However, in our study MB caused a significant reduction in LBP in these patients, and when the pain is reduced, the patients' social burden will decrease and they can return to work or other normal activities. In addition, the radicular pain also decreased significantly in the 2 groups in our study at 24 hours after surgery. Although the reduction in the radicular pain in our study mainly results from the surgical effect and neural decompression, there was a nonsignificant trend toward greater reduction was greater in the MB group.

In our study, there was a statistically significant difference in the ODI scores between the 2 groups, and the functional QOL improved significantly 3 months after the operation in both groups. The ODI score was reduced from 44.56 preoperatively to 9.58 at 3 months after surgery in MB-treated patients. Our findings are similar to those of Kim et al., ${ }^{21}$ who reported a significant reduction in the average ODI score at 3 months after MB injection (from 38.0 at baseline to 27.4 at 3 months). Our findings are also similar to the findings reported by Peng and colleagues in 2 studies. ${ }^{32,33}$ The first of these 2 studies showed that intradiscal MB injection in patients with chronic discogenic LBP resulted in a definite improvement in physical function. ${ }^{33}$ The second study was a randomized placebo-controlled trial of intradiscal injection of $1 \mathrm{ml}$ of $1 \% \mathrm{MB}$ for the treatment of chronic discogenic LBP and demonstrated a reduction in the mean disability score from 48 to 13 after MB treatment and a definite improvement in physical function. ${ }^{32}$ Levi et al. ${ }^{23}$ investigated the change in ODI score in patients with discogenic LBP after a single intradiscal injection of MB; they considered $30 \%$ improvement in function as the categorical success rate and less than $30 \%$ as the categorical failure. They reported that for the ODI, at 1,2 and 6 months after the injection, the categorical success rates were $25 \%, 21 \%$, and $33 \%$, respectively. Similar to our study, their findings showed that the ODI was improved at 6 months after in- jection. However, their final results were in conflict with our findings, as they reported that a single intradiscal injection of MB did not demonstrate overall clinical success in these patients. This difference in findings might be due to the smaller number of patients in their trial; in our study the ODI score was improved significantly in both groups, although the functional outcome was significantly better in MB-treated patients. In our study, the placebo group showed at least a 2-fold increase in the number of patients with moderate disability (i.e., those who were unable to work because of their disability but could manage daily activities). No patient in either group developed severe disability postoperatively. Most (>90\%) of the MBtreated patients were classified as having "minimal disability" (i.e., they could manage daily activities and return to work).

We could find no reports in the literature of allergic reaction to intradermal or intravenous injection of MB. Some studies have reported that intradermal MB injection is a safe, simple, fast, and efficient method for reducing postoperative pain with minimal complications..$^{27,50}$ However, the intrathecal injection of MB can cause neurological deficits. ${ }^{44}$ No single study has ever reported any complications or patient injury as a result of epidurally administered MB. Many experimental and clinical studies, including the 2011 study by Farrokhi et al., ${ }^{13}$ have shown that epidural injection of MB has no adverse effect. In the present study, we ensured that the dural sac was intact during epidural $\mathrm{MB}$ application and so prevented neurological deficits. Also, minimal doses of MB were used to prevent high local concentration. Some studies have reported that intravenous administration of MB turns urine green or even blue at large doses, ${ }^{9}$ but local administration of MB in the present study did not cause any changes in the color of the patients' urine. In addition, $1 \mathrm{ml}$ of MB solution at a concentration of $0.5 \%$ did not change the color of blood or fluids that might accumulate in the Hemovac drains, so it did not lead to the recognition of the patient group based on discoloration of the output. The conclusion is that epidurally administered MB is safe.

MB has been used in medicine for many years with few reports of toxic effects. A study conducted by Gillman ${ }^{15}$ revealed no report of toxicity from MB alone. MB is metabolized to yield $\mathrm{N}$-demethylated products of which azure $\mathrm{B}$, the monodemethyl species, is the major metabolite. ${ }^{54}$ Azure $\mathrm{B}$ is a reversible MAO inhibitor with a competitive mode of action. Of particular significance is that MB and azure B may possess similar therapeutic applications and toxicological profiles, but azure $\mathrm{B}$ is a more potent MAOA inhibitor than MB itself. ${ }^{36}$ This implies that azure B will also contribute to many of the subsequent toxicological and pharmacological effects traditionally associated with MB treatment, such as the neuro- and psychomodulatory effects as well as ST. Petzer et al. ${ }^{34}$ provided the first evidence of the MAO inhibitory actions of azure B and suggested that azure B may be a hitherto underrecognized contributor to the pharmacology and toxicology of MB by blocking central and peripheral MAO-A activity. The use of MB infusion in combination with other 5-hydroxytryptaminergic agents may lead to ST. ${ }^{15}$ Serotonin (5-HT) has long been associated with pain processing and modulation 
in the CNS. ${ }^{11}$ Pivotal studies have shown a spinal analgesic action of 5-HT released from brainstem structures..$^{55,56}$ Some researchers have questioned a major role of 5-HT in descending analgesia ${ }^{48}$ or found it limited to the C-fibers in raphe-spinal pathways. ${ }^{47}$ A 5-HT-mediated central analgesic effect was expected to occur with the use of selective serotonin reuptake inhibitors (SSRIs), but these proved less successful as analgesics than tricyclic antidepressants, which exhibit mixed 5-HT and noradrenalin reuptake inhibition. ${ }^{2,26}$ In fact, only a few SSRIs proved effective for neuropathic pain in clinical trials. ${ }^{45,46}$ After nerve injury, the 5-HT content in the lesioned nerve increases. 5-HT receptors of the 5-HT3 and 5-HT2A subtype are present on C-fibers. Acting in combination with other inflammatory mediators, 5-HT may ectopically excite and sensitize afferent nerve fibers, thus contributing to peripheral sensitization and hyperalgesia in inflammation and nerve injury. In fact, the release of 5-HT into inflamed or injured tissues contributes to peripheral sensitization of nerve fibers. In our study, we excluded the patients who were taking serotonergic drugs because MB inhibits the action of MAO-A, which is an enzyme responsible for breaking down serotonin in the brain, and when $\mathrm{MB}$ is given to patients taking serotonergic psychiatric medications, high levels of serotonin can build up in the brain, causing ST and serious CNS toxicity. Consequently, none of the MB-treated patients experienced ST or CNS toxicity in our study.

In our study, we investigated the use of MB on postoperative pain as a possible alternative to prescribing drugs for controlling postoperative pain through medications that are associated with complications. ${ }^{1,10,19,24,29,39}$ Most patients experience pain at the surgical site in the first few months after surgery..$^{3,7,10,37}$ We think that the most severe discomfort, resulting from soft tissue injury, muscle dissection, and any surgical manipulation, occurs in the first 2 to 3 months after surgery. ${ }^{35}$ In addition, because surgicalsite inflammation usually resolves within 2 months after surgery, the pain also decreases significantly during this period. Therefore, we thought a follow-up period of 3 months was sufficient to evaluate the safety and efficacy of MB for preventing postoperative LBP and radicular pain. Thus the focus of our study was on evaluating the efficacy of $\mathrm{MB}$ in the first 3 months after surgery, and the study was terminated after that point. Our findings suggest that MB can achieve adequate postoperative LBP and radicular pain control in this period. In addition, preventing postoperative pain can help prevent chronic LBP and failed back surgery syndrome (FBSS). Therefore, the object of our study was to prevent LBP, which consequently leads to avoiding chronic LBP and FBSS.

The present study sheds new light on the subject and suggests that more studies with a longer follow-up period may be warranted to further investigate the long-term effect of $\mathrm{MB}$ on the reduction of postoperative LBP and radicular pain and the improvement of QOL in patients who undergo lumbar discectomy.

\section{Conclusions}

In conclusion, greater benefit in clinical outcome measures was seen in MB-treated patients in our study. A sin- gle dose of $\mathrm{MB}(1 \mathrm{ml}$ at a concentration of $0.5 \%)$ for coating the dura and surrounding tissues (facet and muscle) shows promising results in terms of safety, reduction of postoperative LBP and radicular pain, and functional results when compared with placebo 3 months after surgery.

\section{Acknowledgments}

We would like to thank Dr. Heidari for data analysis and Ms. Hosseini for her help. This study was partially supported by a grant from Shiraz University of Medical Sciences, and Apadana Tajhizgostar Co. provided grant support, but they had no role in the design of the trial, the collection, management, analysis, and interpretation of the data or in the preparation or review of the manuscript or the decision to submit.

\section{References}

1. Abrishamkar S, Karimi M, Safavi M, Honarmand A, Safavi A: Effects of intraoperative-intrathecal sufentanil injection on postoperative pain management after single level lumbar discectomy. Middle East J Anaesthesiol 20:839-844, 2010

2. Ansari A: The efficacy of newer antidepressants in the treatment of chronic pain: a review of current literature. Harv Rev Psychiatry 7:257-277, 2000

3. Apfelbaum JL, Chen C, Mehta SS, Gan TJ: Postoperative pain experience: results from a national survey suggest postoperative pain continues to be undermanaged. Anesth Analg 97:534-540, 2003

4. Aronov S, Ben-Abraham R, Givati-Divshi D, Katz Y: Involvement of nitric oxide in clonidine-induced spinal analgesia. Drug Metabol Drug Interact 21:41-53, 2005

5. Astrand P, Määttänen H, Vucetic N, Svensson O: Pain and orthopaedic and neurologic signs after lumbar discectomy: a 2-year followup. Clin Orthop Relat Res (379):154-160, 2000

6. Atlas SJ, Keller RB, Wu YA, Deyo RA, Singer DE: Longterm outcomes of surgical and nonsurgical management of sciatica secondary to a lumbar disc herniation: 10 year results from the Maine Lumbar Spine Study. Spine (Phila Pa 1976) 30:927-935, 2005

7. Becker A, Held H, Redaelli M, Strauch K, Chenot JF, Leonhardt C, et al: Low back pain in primary care: costs of care and prediction of future health care utilization. Spine (Phila Pa 1976) 35:1714-1720, 2010

8. Burke SM, Shorten GD: Perioperative pregabalin improves pain and functional outcomes 3 months after lumbar discectomy. Anesth Analg 110:1180-1185, 2010

9. Cvetković BR, Cvetković VR, Rosić ZV, Milenković D: [Late methylene blue appearance in urine after local treatment of cutaneous fistula in hip osteomyelitis as a first sign of renal failure.] Acta Chir Iugosl 55:117-120, 2008 (Serbian)

10. Donovan M, Dillon P, McGuire L: Incidence and characteristics of pain in a sample of medical-surgical inpatients. Pain 30:69-78, 1987

11. Eide PK, Hole K: The role of 5-hydroxytryptamine (5-HT) receptor subtypes and plasticity in the 5-HT systems in the regulation of nociceptive sensitivity. Cephalalgia 13:75-85, 1993

12. Fairbank JC, Pynsent PB: The Oswestry Disability Index. Spine (Phila Pa 1976) 25:2940-2952, 2000

13. Farrokhi MR, Vasei M, Fareghbal S, Farrokhi N: The effect of methylene blue on peridural fibrosis formation after laminectomy in rats: an experimental novel study. Spine J 11:147-152, 2011

14. Fransen P: Reduction of postoperative pain after lumbar microdiscectomy with DuraSeal Xact Adhesion Barrier and Sealant System. Spine J 10:751-761, 2010 
15. Gillman PK: Methylene blue implicated in potentially fatal serotonin toxicity. Anaesthesia 61:1013-1014, 2006

16. Greca FH, Gonçalves NM, Souza Filho ZA, Noronha Ld, Silva RF, Rubin MR: The protective effect of methylene blue in lungs, small bowel and kidney after intestinal ischemia and reperfusion. Acta Cir Bras 23:149-156, 2008

17. Hadjipavlou AG, Tzermiadianos MN, Bogduk N, Zindrick MR: The pathophysiology of disc degeneration: a critical review. J Bone Joint Surg Br 90:1261-1270, 2008

18. Harvey BH, Duvenhage I, Viljoen F, Scheepers N, Malan SF, Wegener G, et al: Role of monoamine oxidase, nitric oxide synthase and regional brain monoamines in the antidepressant-like effects of methylene blue and selected structural analogues. Biochem Pharmacol 80:1580-1591, 2010

19. Hegarty DA, Shorten GD: A randomised, placebo-controlled trial of the effects of preoperative pregabalin on pain intensity and opioid consumption following lumbar discectomy. Korean J Pain 24:22-30, 2011

20. Huskisson EC: Measurement of pain. Lancet 2:1127-1131, 1974

21. Kim SH, Ahn SH, Cho YW, Lee DG: Effect of intradiscal methylene blue injection for the chronic discogenic low back pain: one year prospective follow-up study. Ann Rehabil Med 36:657-664, 2012

22. Kluger Y, Weinbroum A, Ben-Avraham R, Galili Y, Klausner J, Rabau M: Reduction in formation of peritoneal adhesions by methylene blue in rats: a dose response study. Eur J Surg 166:568-571, 2000

23. Levi DS, Horn S, Walko E: Intradiskal methylene blue treatment for diskogenic low back pain. PM R 6:1030-1037, 2014

24. Marret E, Kurdi O, Zufferey P, Bonnet F: Effects of nonsteroidal antiinflammatory drugs on patient-controlled analgesia morphine side effects: meta-analysis of randomized controlled trials. Anesthesiology 102:1249-1260, 2005

25. Mayer B, Brunner F, Schmidt K: Inhibition of nitric oxide synthesis by methylene blue. Biochem Pharmacol 45:367374, 1993

26. McQuay HJ, Tramèr M, Nye BA, Carroll D, Wiffen PJ, Moore RA: A systematic review of antidepressants in neuropathic pain. Pain 68:217-227, 1996

27. Mentes BB, Akin M, Leventoglu S, Gultekin FA, Oguz M: Intradermal methylene blue injection for the treatment of intractable idiopathic pruritus ani: results of 30 cases. Tech Coloproctol 8:11-14, 2004

28. Oz M, Lorke DE, Hasan M, Petroianu GA: Cellular and molecular actions of methylene blue in the nervous system. Med Res Rev 31:93-117, 2011

29. Ozgencil E, Yalcin S, Tuna H, Yorukoglu D, Kecik Y: Perioperative administration of gabapentin 1,200 mg day-1 and pregabalin $300 \mathrm{mg}$ day-1 for pain following lumbar laminectomy and discectomy: a randomised, double-blinded, placebo-controlled study. Singapore Med J 52:883-889, 2011

30. Parker SL, Xu R, McGirt MJ, Witham TF, Long DM, Bydon A: Long-term back pain after a single-level discectomy for radiculopathy: incidence and health care cost analysis. J Neurosurg Spine 12:178-182, 2010

31. Pearson AM, Blood EA, Frymoyer JW, Herkowitz H, Abdu WA, Woodward R, et al: SPORT lumbar intervertebral disk herniation and back pain: does treatment, location, or morphology matter? Spine (Phila Pa 1976) 33:428-435, 2008

32. Peng B, Pang X, Wu Y, Zhao C, Song X: A randomized placebo-controlled trial of intradiscal methylene blue injection for the treatment of chronic discogenic low back pain. Pain 149:124-129, 2010

33. Peng B, Zhang Y, Hou S, Wu W, Fu X: Intradiscal methylene blue injection for the treatment of chronic discogenic low back pain. Eur Spine J 16:33-38, 2007

34. Petzer A, Harvey BH, Wegener G, Petzer JP: Azure B, a metabolite of methylene blue, is a high-potency, reversible inhibitor of monoamine oxidase. Toxicol Appl Pharmacol 258:403-409, 2012

35. Quaglietta P, Cassitto D, Corriero AS, Corriero G: Paraspinal approach to the far lateral disc herniations: retrospective study on 42 cases. Acta Neurochir Suppl 92:115-119, 2005

36. Ramsay RR, Dunford C, Gillman PK: Methylene blue and serotonin toxicity: inhibition of monoamine oxidase A (MAO A) confirms a theoretical prediction. Br J Pharmacol 152:946-951, 2007

37. Rhyne AL, Blumenthal SL, Frank EH, Hsu KY, Kim KD, Youssef JA, et al: Oxiplex reduces leg pain, back pain, and associated symptoms after lumbar discectomy. Spine (Phila Pa 1976) 37:631-641, 2012

38. Rojas JC, Simola N, Kermath BA, Kane JR, Schallert T, Gonzalez-Lima F: Striatal neuroprotection with methylene blue. Neuroscience 163:877-889, 2009

39. Rømsing J, Møiniche S: A systematic review of COX-2 inhibitors compared with traditional NSAIDs, or different COX-2 inhibitors for post-operative pain. Acta Anaesthesiol Scand 48:525-546, 2004

40. Ruban D, O'Toole JE: Management of incidental durotomy in minimally invasive spine surgery. Neurosurg Focus 31(4):E15, 2011

41. Salaris SC, Babbs CF, Voorhees WD III: Methylene blue as an inhibitor of superoxide generation by xanthine oxidase. A potential new drug for the attenuation of ischemia/reperfusion injury. Biochem Pharmacol 42:499-506, 1991

42. Schirmer RH, Adler H, Pickhardt M, Mandelkow E: Lest we forget you-methylene blue. Neurobiol Aging 32:2325. e7-2325.e16, 2011

43. Schulz KF, Altman DG, Moher D: CONSORT 2010 statement: updated guidelines for reporting parallel group randomized trials. Ann Intern Med 152:726-732, 2010

44. Sharr MM, Weller RO, Brice JG: Spinal cord necrosis after intrathecal injection of methylene blue. J Neurol Neurosurg Psychiatry 41:384-386, 1978

45. Sindrup SH, Bjerre U, Dejgaard A, Brøsen K, Aaes-Jørgensen T, Gram LF: The selective serotonin reuptake inhibitor citalopram relieves the symptoms of diabetic neuropathy. Clin Pharmacol Ther 52:547-552, 1992

46. Sindrup SH, Gram LF, Brøsen K, Eshøj O, Mogensen EF: The selective serotonin reuptake inhibitor paroxetine is effective in the treatment of diabetic neuropathy symptoms. Pain 42:135-144, 1990

47. Sorkin LS, McAdoo DJ, Willis WD: Raphe magnus stimulation-induced antinociception in the cat is associated with release of amino acids as well as serotonin in the lumbar dorsal horn. Brain Res 618:95-108, 1993

48. Stamford JA: Descending control of pain. Br J Anaesth 75:217-227, 1995

49. Stawicki SP, Sims C, Sarani B, Grossman MD, Gracias VH: Methylene blue and vasoplegia: who, when, and how? Mini Rev Med Chem 8:472-490, 2008

50. Tan KY, Seow-Choen F: Methylene blue injection reduces pain after lateral anal sphincterotomy. Tech Coloproctol 11:68-69, 2007

51. Vaccaro A, Patten SA, Ciura S, Maios C, Therrien M, Drapeau P, et al: Methylene blue protects against TDP-43 and FUS neuronal toxicity in C. elegans and D. rerio. PLoS ONE 7:e42117, 2012

52. Volke V, Wegener G, Vasar E, Rosenberg R: Methylene blue inhibits hippocampal nitric oxide synthase activity in vivo. Brain Res 826:303-305, 1999

53. Wainwright M, Crossley KB: Methylene blue-a therapeutic dye for all seasons? J Chemother 14:431-443, 2002

54. Warth A, Goeppert B, Bopp C, Schirmacher P, Flechtenmacher C, Burhenne J: Turquoise to dark green organs at autopsy. Virchows Arch 454:341-344, 2009

55. Yaksh TL, Tyce GM: Microinjection of morphine into the 
periaqueductal gray evokes the release of serotonin from spinal cord. Brain Res 171:176-181, 1979

56. Yaksh TL, Wilson PR: Spinal serotonin terminal system mediates antinociception. J Pharmacol Exp Ther 208:446453, 1979

57. Yorimitsu E, Chiba K, Toyama Y, Hirabayashi K: Long-term outcomes of standard discectomy for lumbar disc herniation: a follow-up study of more than 10 years. Spine (Phila Pa 1976) 26:652-657, 2001

\section{Disclosure}

The authors report no conflict of interest concerning the materials or methods used in this study or the findings specified in this paper.

\section{Author Contributions}

Conception and design: all authors. Acquisition of data: all authors. Analysis and interpretation of data: all authors. Drafting the article: all authors. Critically revising the article: all authors. Reviewed submitted version of manuscript: all authors. Approved the final version of the manuscript on behalf of all authors: Farrokhi. Statistical analysis: all authors. Administrative/technical/ material support: all authors. Study supervision: all authors.

\section{Correspondence}

Majid Reza Farrokhi, Shiraz Neuroscience Research Center, Chamran Hospital, Chamran Blvd., P.O. Box 7194815644, Shiraz, Iran.email: farrokhimr@yahoo.com. 